\title{
On the Development of Group Insurance and Collective Saving in the Federal Republic of Germany and in Great Britain
}

\author{
by Brigitte Reitz *
}

\section{Introduction}

(1) The development of overall economic saving - and particularly of group saving - has become increasingly harder to define since the '70s, both for scientists and practicians on the financial markets. The need for thorough investigation of the factors influencing monetary quantities must therefore be regarded as urgent, not only as an intellectual exercise but mainly for the purpose of providing the competitors on the markets for savings funds (banks, insurance companies, etc.) with the necessary basis for their marketing efforts.

(2) Attempts at forecasting combined with the assorted marketing activities had up to then appeared straightforward due to the fact that previously the development had largely been stable and uniform. The certainty of high growth rates of Gross National Product, fast rising wages and salaries, low rates of inflation, as well as consistent legislation had made it possible for the accumulated savings - within the individual as well as the collective sphere - to be calculated quite reliably in advance.

(3) In recent years however the overall economic development in West European national economies has to a growing extent been characterized by disruptions in structures as well as trends, such as reduced long-term growth prospects, the slowdown of demographic development, reorientation of economic policy, as well as possible political or legal changes - particularly within the sector of group saving - which are aimed at greater regulation of private economic activity. This has an immediate impact on future possibilities and opportunities for the insurance industry to participate in this financial market.

(4) All this together with the enormous expansion of mass incomes in recent years, which has multiplied and intensified competitive relations on the financial markets, has made necessary some general re-orientation. For one thing, the prospective development of the volume of savings - and especially that of group saving - could therefore no longer be managed by means of mechanical extrapolation, but a thorough analysis of all influential factors had to be undertaken; and, for another, there was a greater need for well-founded long term planning for the competitors on the financial markets.

* Economist, PROGNOS AG, Basle, European Center for Applied Economic Research. 
(5) PROGNOS has thoroughly investigated this subject on behalf of the Geneva Association. The present paper is based on two studies which were carried out in 1975 and 1976 , respectively. 1

The selection of the Federal Republic of Germany and Great Britain as the survey countries was mainly due to the legal changes that have taken place there and which have led to increased uncertainty. These problems had been heightened by the fact that important information and statistics were either dispersed over a multitude of most recent publications, were very difficult to obtain, or not available at all. On the other hand, a great need existed for summarized and comparative information.

The comparative analysis of two countries was furthermore intended to highlight gaps in the information base and to give indications of possible alternative solutions to the problems in question.

\section{Aspects and forms of the saving process in a national economy}

(1) Before touching upon the strictly marketing-oriented problems of financial intermediaries it should be stressed once more that research into the saving process and of group saving in particular - is of immediate relevance for the national economy.

Economic growth without inflation is not possible unless the investment process is accompanied by saving. Formation of real capital must always go hand in hand with a renunciation of current consumption. If this is not to be brought about by compulsory saving - inappropriate in principle in liberal and democratic societies - or by undesirable price increases by companies, the only possibility is financing by voluntary savings to the same amount.

Outstanding importance must therefore be attributed to the activities of financial intermediaries for the purpose of acquiring funds and channelling them to the end users (investors), especially from an overall economic viewpoint.

(2) Whoever wants to define the role of saving in the development of a national economy must therefore not stop short at a mere global examination of the volume of savings, but has to rely on an analysis of the processes which control the flow of funds to their end users, the investors. After all, it is the scope and structure of investments that determine the growth prospects of an economy.

(3) Saved funds are usually either :

- invested by the saver himself ;

- put directly at the disposal of deficit units (companies) for investment purposes ;

- entrusted to financial intermediaries.

By far the most important application in developed economies is financial mediation.

(4) Financial intermediaries function as reservoirs for inflowing funds - making possible an altogether profitable portfolio policy - as well as processors of terms and risks. On account of their mediating role between money lenders and users, they carry out an indispensable function for the present-day overall economy because no smoothly

1 See : "Etudes et Dossiers" No. 5 (December 1975) and No. 13 (May 1977) of the "Geneva Association" - Association Internationale pour l'Etude de l'Economie de l'Assurance, Geneva. 
operating financial transfer would be conceivable without them under the complex conditions prevailing on modern financial markets.

(5) The (belated) kindling of scientific interest in financial intermediation coincided with a growing awareness on the part of the intermediaries of their own market situation. The rise in mass incomes combined with even higher and more sophisticated standards set by the investors made all kinds of financial enterprises pay more attention to the acquisition of funds if they did not want to run the risk of losing valuable market shares. In the meantime, the market of saved funds had been covered by a network of financial institutions, all of whom were out to profit from an acceleration of the deposit function. In order to attract funds, the preferences of potential money lenders had increasingly to be taken into account, thus making marketing considerations an essential factor also in the financial sector.

(6) Four kinds of preferences determine the investment decisions of moneylenders and must accordingly be regarded as basically important by financial intermediaries :

1. moneylenders always give preference to high revenues over lower ones;

2. moneylenders prefer more safety to less safety;

3. moneylenders choose one investment alternative in preference to others if it has a higher degree of liquidity ;

4. moneylenders are inclined towards such investments which are coupled with as many additional services as possible.

The weight of these factors naturally shifts with changes in the legal, macroeconomic, or psycho-social overall conditions.

The field of competitors on the financial markets thus presents itself as follows :

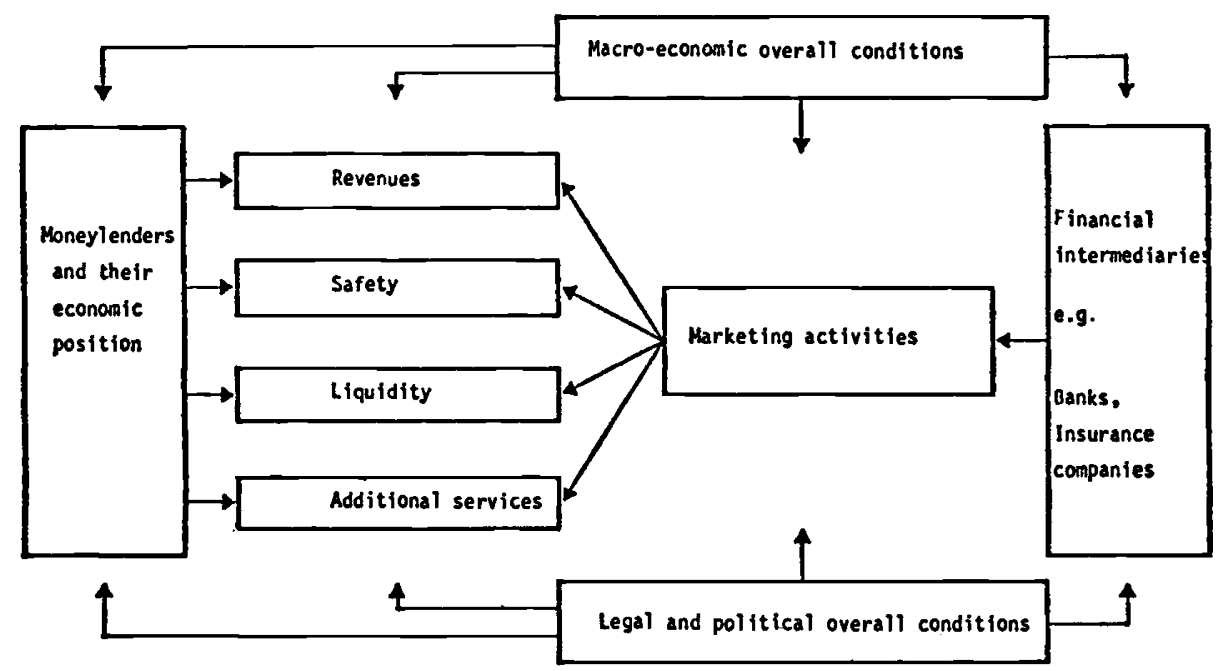


(7) If the preferences of the moneylenders have so far been presented in such a global manner, the reason is that total competition prevails on the market for savings funds between the various forms of saving. Marketing decisions of financial intermediaries must therefore also be based on knowledge of the overall situation. The market analysis in section $\mathbf{5}$ of this paper is also founded on this fact.

After a short glimpse at competitive relations, what follows will mainly be an examination of the market for group savings funds - especially in the sector of employers' pension schemes (second pillar) and the development prospects of the insurance industry on this market (see diagram below). In order to meet the specific interest of the insurance industry, those funds which have been saved within the scope of occupational arrangements for individual employees have also been taken into account.

\begin{tabular}{|c|c|c|c|c|c|c|c|}
\hline Forms & & $1 \mathrm{st}$ & 2nd & Pillar & & & 3rd \\
\hline $\begin{array}{l}\text { Factors } \\
\text { of influence }\end{array}$ & $1+44$ & provision & State & Insurance & Banking & Company & $\begin{array}{l}\text { Indi- } \\
\text { vidual } \\
\text { saving }\end{array}$ \\
\hline $\begin{array}{l}\text { Legal } \\
\text { and } \\
\text { political } \\
\text { impact } \\
\text { Macro- } \\
\text { economic } \\
\text { impact } \\
\\
\text { Psycho- } \\
\text { sociological } \\
\text { impact }\end{array}$ & 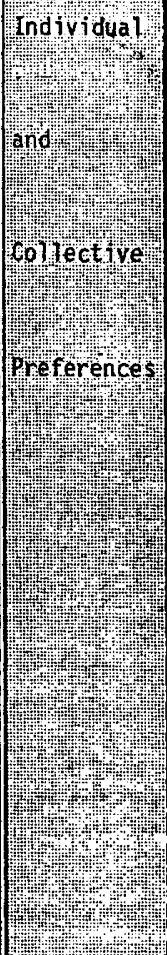 & & & & & & \\
\hline
\end{tabular}




\section{Important competitive relations on the markets for group savings}

(1) The interface between government provision and group saving by private industry has to be regarded from three points of view :

1. interconnection;

2. complementary and supplementary nature;

3. competition.

To begin with, it should be stated that the majority of the contributions to the government scheme do not represent savings from an economic viewpoint, since these old-age pensions are financed according to the pay-as-you-earn principle, i.e. instead of actual saving merely inter-personal transfers are taking place.

Ad. 1. Occupational pension schemes are legally regulated in both countries being surveyed here and the official and private sectors are therefore not independent of each other. Legal minimum demands for the second column are, moreover, suited to promote the generating of such funds. In Great Britain, interconnection is particularly close on account of the partial alternative concept between government and private pensions (contracting out).

Ad. 2. Since the government schemes so far have in principle only provided basic security, considerable market potential exists with rising incomes for funds which are not administered by the government. This is the reason why it has been repeatedly observed in West Germany as well as in Great Britain that higher government benefits coincided with an increase in the number of private policies, since the discussion concerning increase always showed clearly how low the benefits had been previously.

Ad. 3. In the long term view keener competition must be expected. If the contributions to the government scheme were to be further increased on account of the growing percentage of people of pensionable age, weaker economic growth, or rising benefits, this might paralyze private initiative.

(2) From the empirical point of view, the competition between banks and insurance companies on the market for group savings funds differs widely in the two countries under survey. While in the Federal Republic of Germany the banks have up to now kept more or less out of this field, their role in Great Britain has already become tradition. This difference is not a legal one but is based on what is customary.

In order to completely describe in theory the kind of competition which is possible in principle, it seems advisable to start out from the preferences of the moneylenders :

- the preference for revenues is met by both banks and insurance companies. It is of vital importance for both intermediaries to make profits on the investment of monetary funds by means of a clever portfolio policy, with part of this profit being, in turn, put at the disposal of the moneylender. In this sector, banks and insurance companies have the same opportunities in principle;

- the inclination towards security is best taken care of by the insurance companies. The banks meet this request only inasmuch as they seek to invest money at favourable terms and thus to give a good yield. In addition, they handle transfer of payments and provide information of many kinds. Insurance companies, on the other hand, are in a position to cover risk by means of compensation within the groups 
in question. Beyond satisfying particular demands, they always offer basic security regarding the profitability of an investment, i.e. the promise to pay at least the actuarial rate of interest must be kept ;

- the preference for liquidity should in a strict sense be left out on a market for longterm investment of funds, but on account of the practice of granting loans to the original moneylenders it does play a role again. In the Federal Republic of Germany, for instance, policy loans are regulated by law. Banks handle this differently;

- in the case of additional services, banks and insurance companies initially have equal chances with regard to information, administrative assistance, and service. An advantage of the banks would be the existing connection with enterprises for the purpose of handling payments, previous credit loans, and financial planning. The only advantage of the insurance companies would be the coverage of risk.

The following diagram shows a summary of the field of competition. The number of plus symbols - three maximum - characterizes the relative strength of the position of the competitor

\begin{tabular}{|l|c|c|}
\hline \multicolumn{1}{|c|}{ Competitor } & Banks & Insurance companies \\
\hline Preferences & +++ & +++ \\
Revenues & + & +++ \\
Security & + & ++ \\
Liquidity & +++ & ++ \\
Additional services & & \\
\hline
\end{tabular}

(3) In the strictest sense, an investigation of the role of the enterprises in the market for collective saving could only be undertaken for the Federal Republic of Germany, where direct accumulation of funds from employers' pension schemes in the enterprise in question is legally laid down, while in other countries independent (selfadministered) funds have to be set up by the enterprise for this purpose. The major features of an autonomous administration of the funds for occupational pensions are however identical, regardless of the legal form.

The following main advantages of self-administered funds are emphasized:

- the cash-flow argument : the funds do not have to leave the enterprise but can on the contrary - work for it in the form of investments. The possibility of loans on the cash value of the policies, on the other hand, is less attractive from the viewpoint of the enterprise;

- the savings argument: the potential gain of the insurance companies (beyond the short return of interest) could be made by the enterprise itself ;

- the social argument : funds for occupational pensions could, for instance, be used in the meantime for benefits to employees.

As disadvantages, on the other hand, the following points are mentioned :

- lack of investment know-how as well as limitations on investments of relatively small amounts; 
- the necessity of at least partial coverage of risk by insurance companies;

- high cost of administration;

- limited information and routine.

Obviously, all these disadvantages apply to small and medium-sized enterprises. In addition, new legislative measures which have created new bases for collective saving have to be taken into account.

\section{A medium term forecast of the development of occupational pension schemes and the market share of the insurance industry}

(1) As to method, a scenario model was selected. This kind of approach guarantees that qualitative as well as quantitative factors influencing the future development of a variable - in this case : collective savings - can be integrated in a forecast. Furthermore, the explicit, thorough and detailed analysis of each single determining factor provides the possibility of "re-running" the scenario time and again at any desired interval, and to update the results in accordance with the latest available information. The scenario can therefore do much more than provide a final answer to questions regarding the future : it puts the user in a position to find for himself up-to-date valid answers by means of an approved method.

(2) Especially in situations of upheaval - as was the case for instance in recent years within the domain of financial markets - the scenario method has - according to all accumulated experience - proved that it is worth more than purely quantitatively oriented mathematical or statistical methods, for example:

- trend extrapolation ;

- correlation and regression analyses;

- exponential smoothing,

as well as other forms of time series analyses.

This is due to the fact that the latter, in accordance with their layout, register the patterns of the past and extrapolate them in one way or another. When structural disruptions occur, however, they are bound to fail.

(3) The range of factors influencing collective saving and market prospects of the insurance industry within the entire area of employers' pensions is extremely complex.

In order to avoid an overcomplication of the identification of the basic trend by also including problems of daily occurrance, it was decided to settle for a medium-term perspective.

In the short term, specific cyclical and erratic factors can cover up the basic trend and thus render useless such projections which are based on erroneous data. Examples of the disturbing influence of special factors which are effective only for a short time have been in evidence in both countries under survey particularly strongly in most recent years : a marked reluctance to set up new schemes - caused by lengthy phases of legislation - coincided in each instance with a particularly unfavourable cyclical situation and negative state of the labour market. As all our interviewees confirmed unanimously, market observations were exceedingly hard to interprete for this reason and could definitely not be extrapolated. 
(4) With all this in mind, the following main factors of influence emerged, which had to be dealt with in the scenario:

- legal and political influences:

- direct laws for the regulation of occupational pension schemes,

- laws for the formation of assets and government pensions;

- macro-economic influences;

- sociological influences:

- attitude of trade unions, co-management,

- scale of social priorities.

The diagram on the following page describes the model approach.

From the discussion of the effect of each of these factors of influence and the subsequent interrelation of direction and strength of their impact the table of forecasts up to 1990 was developed (page 62).

(5) The influence of legal and political factors on the future development of collective saving and the market prospects of the insurance industry has been chosen as the first step in building up the scenario, since in the two countries under investigation, basic data had been set up from that direction. The nucleus of our observations was the direct legislation on employers' pension schemes.

It has been assumed that the new laws will - at least in their structure and general approach - in principle be retained in the same form as they presented themselves at that time. This essential assumption has not been seriously questioned by any of our interviewees and up to now has proved correct.

The study had to be undertaken separately for the two countries in question since - in spite of the similarity of the objective - nearly diametrically opposed impacts on old-age saving organized by private industry and the possibilities of insurance within this sector have been generated by the divergent legislative provisions.

(6) For the Federal Republic of Germany, the "Law for the Improvement of Occupational Pensions' of December 1974 had three objectives, which were, however, not independent of each other :

- it was intended to make old-age provisions better and in particular safer for all those employees who already had the security of old age pensions;

- it was to promote the expansion of occupational pension schemes;

- it was to free insurance saving as a form of group pension scheme from excessive tax burdens and thus make it more attractive.

The adequate practical design of this law has an immediate impact on the future development of the volume of group savings and the market share held by the insurance industry.

Considering all these arguments, the conclusion had to be drawn that strong incentives have been set for private industry. For the years to come, that is to say beyond the immediate future - once everyone is used to the new legal situation - a disproportionate expansion of collective saving has to be expected as compared with the development in the past as well as with old-age provisions. Special tax reductions for insurance saving will have an additional positive effect on the chances of the 

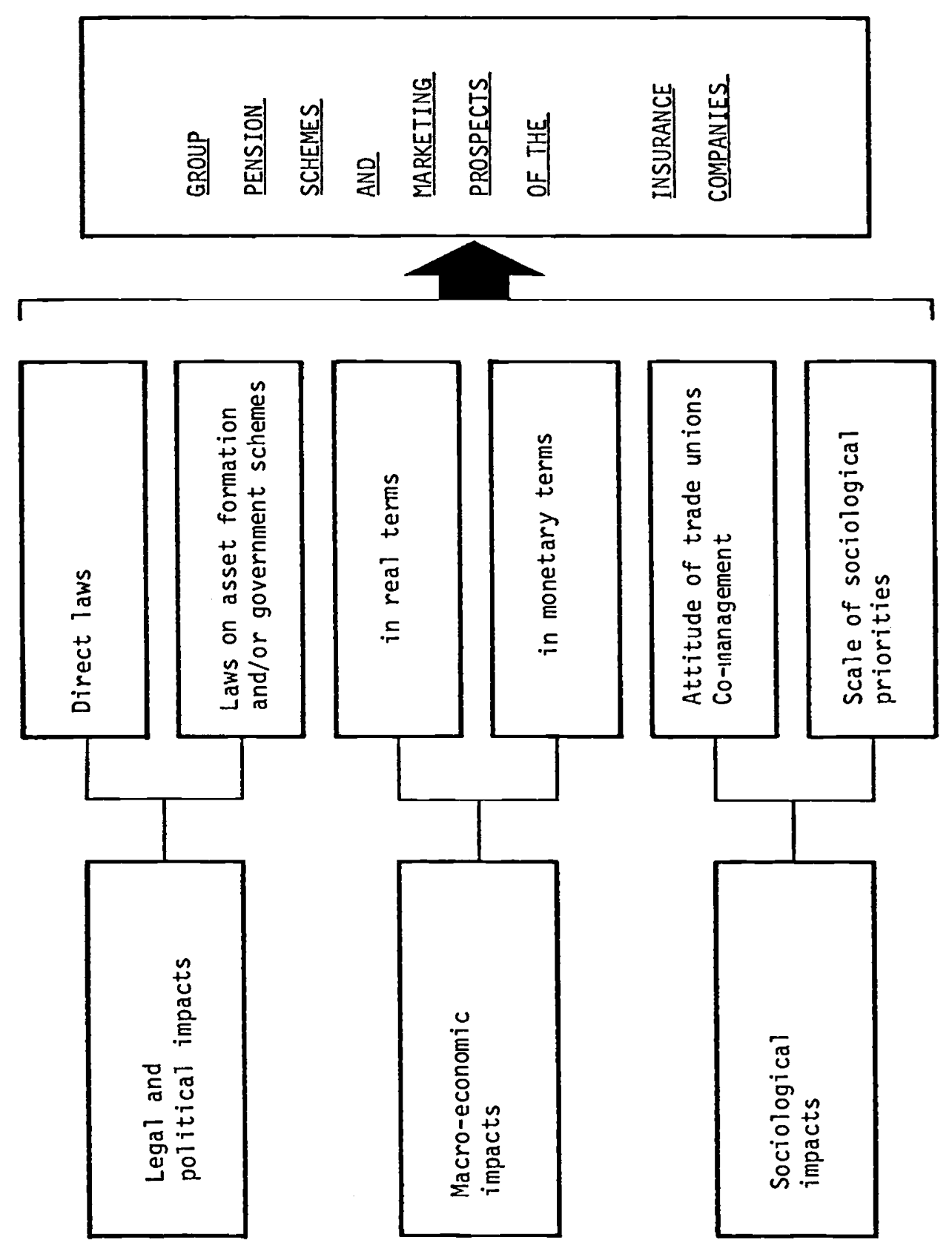
insurance industry within this sector. The fact that this business has initially developed only sluggishly does not contradict this assumption but is rather due to "teething" difficulties and uncertainties.

It may thus be concluded that a powerful expansionary impact on old-age saving - and in particular on the market share of the insurance industry - will develop from legal conditions in Germany.

Although the general socio-policital scene is restless - especially on account of the ongoing discussions of the financial situation of the German government scheme we have, after thorough investigation of this whole complex, come to the conclusion that no serious danger for the development of old-age saving through private insurance companies is likely to follow.

(7) In Great Britain, on the other hand, quite the opposite direction was taken by the Social Security Pensions Act which took effect in April 1978: government minimum prescriptions and government regulations - contrary to initiative on the part of private industry - are to guarantee better old-age pensions. On account of the partial alternative arrangement between government pensions (financed on a pay-asyou-earn basis) and private pensions, there is still the option of making (additional) provision through private insurance, which is to say in this case, by saving up funds (collectively). Special regulations for the insured industry have not been issued.

It is to be expected that the new legal regulations alone - if these are regarded by themselves - will produce a slightly dampening effect on private collective saving. Although - while rating this influence a negative one - we deem it very weak, this is because experience has shown that all debates about social security have so far resulted in a new impetus for all institutions concerned. Within this extremely modest scope, the prospects of the insurance industry are likely to prove particularly positive, not least on account of the overcomplication of the management of employers pension schemes, on the one hand, and the excellent know-how of the British insurance companies, on the other.

(8) In the medium term, the impact of overall economic development on the expansion of collective saving and on the market share of the insurance industry is of the greatest importance in the scenario. This is due to the fact that it is the growth of the National Product which always determines the scope of what is left to be additionally distributed in a national economy - and the margin for the expansion of occupational pension schemes must after all, also be oriented accordingly.

Since, for the time being, no great legal changes are to be expected, the mediumterm outlook - and especially the quantitative conclusions - can to a great extent rely on some basic macroeconomic data. Another aspect of this reasoning is the fact that in the meantime (in the FRG as well as in GB) nearly two-thirds of the expansion of the insurance business within the sector of occupational pensions results from current contracts or from the adaptation of obligations to general economic development. It is therefore the latter which largely determines the inherent dynamics of the growth rates.

Regarded from the viewpoint of overall economic development, the future prospects of collective saving through insurance companies in both countries being surveyed here can be regarded as positive. Economic growth continuing over a long 
period and a decreasing inflationary tendency might have the result of producing positive impulses from both the ability as well as the propensity to save.

In spite of different courses taken by individual growth development, very similar positive effects on collective saving can be expected all the same for the next $10-15$ years in the FRG as well as in GB.

This conclusion has been reached in spite of the different starting positions in both countries (in Great Britain, the rate of inflation is higher but real economic growth slower), because in the medium term, economic developments can be expected to move closer together rather than move even further apart. Moreover, according to experience gained recently - particularly in Great Britain - the propensity to provide for the future is not paralyzed to such an extent by inflation as had been previously feared in many quarters.

Some important key figures upon which the forecasting tables are based have been summarized in the following chart:

Table - Average growth rate of economic key figures

\begin{tabular}{|c|c|c|c|}
\hline $\mathrm{C}^{\text {Period }}$ & $1975 / 76$ & $1976 / 82$ & $1982 / 90$ \\
\hline & \multicolumn{3}{|c|}{ Federal Republic of Germany } \\
\hline GDP, constant prices & 5.7 & 3.6 & 3.0 \\
\hline $\begin{array}{l}\text { GDP by industry of origin, const. } \\
\text { prices, Banking and Insurance }\end{array}$ & 6.7 & 4.3 & 3.5 \\
\hline \multirow[t]{2}{*}{ GDP, implicit price deflator } & 2.7 & 4.0 & 4.0 \\
\hline & \multicolumn{3}{|c|}{ Great Britain } \\
\hline GDP, constant prices & 1.4 & 3.0 & 2.6 \\
\hline $\begin{array}{l}\text { GDP by industry of origin, const. } \\
\text { prices, Banking and Insurance }\end{array}$ & 0.8 & 5.2 & 3.7 \\
\hline GDP, implicit price inflator & 15.5 & 10.5 & 8.0 \\
\hline
\end{tabular}

Source : PROGNOS AG

(9) With regard to sociological impacts on collective provision, a change has taken place in recent years inasmuch as far greater attention has been paid to this issue than ever before. The legal changes and the accompanying discussion naturally contributed largely to this growing interest. 
Another aspect which probably plays a decisive role is the fact that a higher living standard generally makes people more inclined to pay attention to those needs which are not of immediate vital urgency, for example the problem of security for old age. Quite generally it must also be taken into account that past experience has apparently taught that a one-sided policy directed towards raising nominal wages while real economic development is lagging behind, mainly fosters inflation while it cannot in the long run raise the living standard of the employees to the hoped for extent.

The extent to which the growing interest in provision is also reflected in a corresponding growth of collective saving as organized by private industry and/or a higher share for the insurance industry depends on the chances of realization of the alternatives which are at present being discussed by employers and trade unions. No distinct results are taking shape yet. On the whole, the sociological influence on collective saving within the context of our scenario is only of secondary importance.

Within the framework set up by legislation and macro-economic development, the effect for the FRG can be described as slightly positive and that for GB - on account of contradicting efforts - as more or less undefined.

(10) The types and relative strengths of influential factors of the scenario facets should be listed once more in toto.

Types and strength of impact of the influential factors on the development of the insurance industry for collective funds

\begin{tabular}{|l|c|c|}
\hline \multicolumn{1}{|c|}{ Country under survey } & FRG & GB \\
\hline Legal and political impact & & \\
Macro-economic impact & & \\
Sociological impact & $\mathbf{D}$ & $=$ \\
\hline
\end{tabular}

$$
\text { Explanation: } \begin{aligned}
\Delta & =\text { strong positive impact } \\
\Delta & =\text { strong negative impact } \\
\Delta & =\text { weak positive or negative impact } \\
= & =\text { undefined impact }
\end{aligned}
$$

\section{Source : PROGNOS AG}

(1) To put the discussed effects of varying strength and direction into figures is of course not without problems. All the same, we deem it justifiable to regard the following growth rates as a practicable approach to reality on account of all the quantitative projections and qualitative considerations undertaken within the selected scenario. 
The development of the insurance industry with regard to collective funds - Annual growth rate on a five-year average in percent -

\begin{tabular}{|c|c|c|c|}
\hline $\begin{array}{l}\text { Country } \\
\text { under survey }\end{array}$ & Period & $1980 / 85$ & $1985 / 90$ \\
\hline FRG & 14 & 10 & 8 \\
GB & 11 & 14 & 10 \\
\hline
\end{tabular}

\section{The market potential and the marketing prospects of the insurance industry}

(1) Our forecast of collective insurance saving, according to which overproportionate chances of development are seen for the insurance industry as compared to general economic growth, was naturally built up on the presumption that any further market potential will be fully and intelligently utilized. Very promising possibilities exist in this respect.

(2) We quite generally assume that the manifold needs of the employees for (collective) provision and security are by no means satisfied yet. This does not only leave an approach open for the insurance industry to increase its market share for collective funds by means of clever marketing, but the limits of this market could furthermore be extended in the future beyond the scope of mere structural shifts.

(3) An as yet unexhausted potential for the insurance industry within the range of old-age provision was found particularly in 5 target groups :

- with the employees of small and medium-sized enterprises;

- with low-income blue and white collar workers ;

- with women ;

- with (executive) employees earning above-average salaries (owner executives);

- with international business, mainly in aspiring companies with growing international activities.

These conclusions apply to GB as well as to the FRG.

(4) We rate the chances for an exploitation of this potential as good to very good. Before discussing individual aspects, we wish to stress again that the motivation of providing for old age on the part of the employees of a company may become more marked in the future. Experience has shown that - once basic needs of consumption have been met - the interest shifts to the increase of such benefits which serve to secure the attained level also in the long run. This will generate a trend towards further positive development of occupational pension schemes and within this scope, on account of special possibilities to satisfy preferences for security, also towards insurance. 
(5) Provisions for the employees of small and medium-sized companies are poor in both countries. According to the observations of experts it seems quite probable beyond the scope of possible general improvement - that the insurance companies acquire additional funds which have so far been managed by the enterprises themselves or by specifically set up foundations. These opinions are mainly based on the observation that the financial management of small and medium-sized companies can (in the long run) hardly cope with the administration of the funds generated by occupational pension schemes.

Intensive interviews with experts for the purposes of a PROGNOS study of the financial market have moreover given rise to the impression that in the FRG, the advantageousness of pension reservations mechanism has up to now been largely overestimated by small and medium-sized companies : in the post-war years, such funds were highly estimated as a "cheap" source of self-financing on account of the still unsatisfactory availability of capital for investment. In the meantime however it had to be realized - in many cases even most painfully - ever since the new law has come into force that pension reserves are also coupled with respective payment obligations. According to this development - and in view of the probability of further growing disenchantment with the realms of business enterprises - the chances of the insurance industry, which gives and keeps clear and exactly calculable promises of payments, should definitely grow for the acquisition of funds from provision in small and medium-sized business establishments.

For Great Britain it must be added, on the one hand, that the rules for occupational pensions have become so complicated on account of the new laws that even experts find it hard to penetrate them in detail. On the other hand, this factor might be (over)compensated by direct competition with the new State scheme.

(6) Low-salaried blue and white collar workers everywhere are under-provided for compared with the average population.

In the FRG, positive incentives for better provision come from the public discussion of the issue of asset forming policy as well as from encouragement both from the trade unions and individual entrepreneurs. This is above all favourable for the insurance industry because tax limits for direct insurance in the case of low wages and salaries do not yet apply. On the other hand however there is very little inclination on the part of the "givers", the enterprises - to make further provision for lowsalaried and mostly easily replaceable employees in view of the medium-term and probably longer lasting unemployment.

In Great Britain, too, the situation is divided. The new law, which still makes it possible to neglect whole groups of workers - and thus also of lower-salaried white and blue collar workers - in spite of the main law on non-discrimination, will at the same time bring some positive impulses via minimum regulations. But on account of the expected future development of the State scheme, this will only partially concern private insurance companies.

(7) Under-provision for women is definitely documented in Great Britain and has especially attracted the attention of legislation. For the FRG, statistical data are lacking; the situation is however judged to be similar according to all accumulated experience. 
In Great Britain, the prohibition of discrimination will most certainly result in additional collective funds for women which should also be reflected in new contracts for the insurance companies. This road is moreover smoothed by informative pamphlets which are specially tailored to fit the requirements of women. In the FRG, nothing comparable has come about so far.

(8) International business is increasingly gaining importance because with closer international interrelation of national economies, trans-frontier connections among combines and direct investment abroad by individual enterprises also grow. This market segment is of particular interest to the insurance business because multinationally oriented enterprises by tradition already have good to very good old-age pension schemes, but also because these - as compared with other enterprises of a similar structure and of the same size group - put an above-average percentage of collectively saved-up funds under the management of insurance companies. An additional market potential is arising from smaller aspiring and more and more internationally active companies.

With regard to quality, the market potential in international business differs greatly from the average. On this level, mainly a service especially tailored to the requirements of the combine in question and to fit the conditions prevailing in the respective country is given preference : a service that can obviously best be offered by the insurance companies.

(9) As with international business, the market segment of above-average salaried (executive) employees requires special know-how on the part of the insurer since the preferences of this group are particularly sophisticated. Even now, provisionary old-age saving in this group is larger than that of other white or blue collar employees - in absolute terms as well as in percent of the salaries. In spite of this fact, we had the impression in both countries that within these quarters great interest still exists in additional collective saving. The form of insurance saving as lump sum insurance is getting increasingly popular in this respect.

In GB, particularly generous provision for executive employees and "owner executives" was made possible by a change in the tax law and since then, this newly opened up market gap has actually proved a sales hit - in spite of the social contract.

In the FRG, the same trend is taking shape. While tax laws prove a hindrance, it has become quite apparent that by means of a clever product policy on the side of the insurance companies, additional approaches can be opened up.

(10) It fits the greater complexity of the market of group savings that the marketing of the insurers has not yet reached the same level as their activities in the sector of individual contracts.

Regular thorough analyses of the preferences of the multilayered demand which - on account of quick changes in legal, macroeconomic, and sociological overall conditions is also subject to continuous changes - is of particular importance on the market for group saving as the basis of all marketing decisions.

According to the opinion of observers, a general pent-up demand still seems to exist, especially in the FRG, while in Great Britain rather only delaying effects are apparent on account of the longwinded to and fro of legislation, and lastly, moreover, on account of the social contract. 
(11) The PROGNOS interviews have shown that within the marketing mix, the "sales policy" in the sense of excellent staff training or selection is to be given first priority by far. This mainly on account of the fact that competitive pressure on the part of other intermediaries for the particular forms of investment they offer is very strong while the "product" insurance is abstract and therefore needs explanation.

Experts have time and again spotted indications of the possibility that a large percentage of the business potential of the insurance companies is only lost because quite a number of their "salesmen" treat companies with multiple pension scheme requirements for their employees the same as "any average head of a family" with simple needs.

(12) The place of second importance within the list of sales policy tools is the "product policy" within the sense of a tailor-made range of provision programmes. In Germany, for instance, the opinion was voiced in some instances that paradixocally, the insurance companies often forfeit market potential because they are bent on urging the enterprises to buy too much insurance saving and thus lose the business altogether. It may however be advisable to start out by offering partial arrangements based on already existing occupational pension facilities which may make an enterprise more readily inclined to expand its business relations with the insurance company in question, provided the initial solution was satisfactory.

(13) The price policy in the classical sense is of somewhat minor interest to the insurance industry because on account of conservative calculation habits and (in the case of the FRG) very strict regulations, there is hardly any margin left. An interesting issue in this context however is the possibility of "with profit" contracts, thus keeping the costs of collective insurance saving low. The insurance industry should stress the fact even more that it had been exceedingly successful with its investment policy much more so than anybody would have expected on account of the drastic fall in share prices since 1973 and much more than it even seemed possible. In both countries, the insurance industry achieved returns which by far exceeded the average of the different forms of investment. This aspect is intensified by the discussion of the problem of adapting regular employers' pension payments to the current economic situation, because investment with insurance companies probably guarantees a sufficiently dynamic development of these benefits merely on account of the profits made (and redistributed) by the insurance companies.

(14) Advertising, too, plays a minor role in the acquisition of collective funds, while a careful information policy, on the other hand, is very important. The insurance industry should, in this context, emphasize its special characteristics as distinct from the other competitors :

security against risk

- in the form of direct security against invalidity and death;

- in the form of security against unpredictable investment losses (since it must at least guarantee the actuarial rate of interest which is not the case with any of its competitors for collective funds !) ;

- in the form of security against unexpected high outgoing payments or sudden loss of liquidity - an argument which goes far with small and medium-sized enterprises. 
(15) The indication of the possibility of a "tailor-made pension scheme from one and the same source" for the employees of an enterprise is directly linked with the approach described above: the insurance company can guarantee to take over administration, handling and organization of the complex of old-age pensions and is in a position to offer a complete set of pension plans which have been conceived particularly with a view to the range of preferences of a particular enterprise.

(16) The result of all that has been said should be that the prospective chances of the insurance companies on the market for group saving are to be assessed optimistically - in spite of many adversities. 